\title{
Never events and hospital-acquired conditions after kidney transplant
}

Linda J. Chen, MD; Zhobin Moghadamyeghaneh, MD; Mahmoud Alameddine, MD; Anupam K. Gupta MD; George W. Burke, MD; Gaetano Ciancio, MD

Department of Surgery, Division of Transplant Surgery, Jackson Memorial Hospital/University of Miami, Miami, FL, United States

Dr. Moghadamyeghaneh had full access to all of the data in the study and takes responsibility for the integrity of the data and the accuracy of the data analysis.

Presented as a poster presentation at the American Transplant Congress (ATC), June 13, 2016, Boston, MA, USA. Presented as an oral presentation at the 26th international congress of the Transplantation Society (TTS), August 18-23, 2016, Hong Kong

Cite as: Can Urol Assoc J 2017; Epub ahead of print. http://dx.doi.org/10.5489/cuaj.4370

Published online November 1, 2017

$* * *$

\section{Abstract}

Introduction: Never events (NE) and hospital-acquired conditions (HAC) after surgery have been designated as quality metrics in healthcare by the centres for Medicare and Medicaid Services (CMS).

Methods: The Nationwide Inpatient Sample (NIS) database 2002-2012 was used to identify patients underwent kidney transplant. Multivariate analysis using logistic regression was used to identify outcomes and risk factors of HAC and NE after transplantation; however, we were limited by using a retrospective database missing some important variables specified for the kidney transplant, such as some operative factors, donor factors, and cold and warm ischemia times.

Results: Among 35058 patients who underwent kidney transplant, there were 11 NEs, all of which were due to retained foreign bodies. Among HAC after surgery, falling was the most common (44.9\%), followed by poor glycemic control (21.7\%), vascular catheter-associated infection (21\%), and catheter-associated urinary tract infection (8\%). HAC and NE after surgery lead to a significant increase in mortality (adjusted odds ratio [AOR] 2.49; $\mathrm{p}=0.04$ ), hospitalization length (13 vs. 7 days; $\mathrm{p}<0.01$ ), and total hospital charges (\$231 801 vs. \$146 717; $\mathrm{p}<0.01)$. A significantly higher risk of HAC or NE was seen for patients who had more loss of function before surgey (AOR 3.25; $\mathrm{p}<0.01$ ) and patients expected to have higher postoperative mortality before operation (AOR 1.62; $\mathrm{p}=0.03$ ). 
Conclusions: Despite the limitations of the study, we found HAC and NE significantly increase mortality, hospitalization length, and total hospital charges of kidney transplant patients. Quality improvement initiatives should target HAC and NE in order to successfully reduce or prevent these events.

\section{Introduction}

The quality and safety of patient care in hospitals are important aims of National Quality Forum (NQF) in the US ${ }^{1,2}$. Never Event (NE) and Hospital Acquired Conditions (HAC) as adverse serious events that are largely preventable are reliable measurements of the quality and safety of patient care ${ }^{1,2}$. NE and HACs also have a significant financial impact on the US healthcare system ${ }^{3}$. It has been estimated that payments for surgical NE amounted to over $\$ 1.3$ billion during $1990-2010^{4}$. Eliminating surgical NEs is necessary to limit harm to patients ${ }^{4}$. Understanding the impact and frequency of these conditions can help to design the best preventative strategies.

NE was defined by National Quality Forum (NQF) in 2006 which includes 28 reportable events in healthcare ${ }^{2}$. The list includes obvious unacceptable errors. However, not all the events are indicative of obvious negligence ${ }^{2}$. A goal of quality improvement is to reduction of never events to zero. In this line, Centers for Medicare and Medicaid Services (CMS) adopted the nonreimbursement policy for some of the events with the name of "non-reimbursable serious hospital-acquired conditions" in order to motivate hospitals to accelerate improvement of patient safety ${ }^{2}$. Investigating patient characteristics and operative factors with the events may help improve current prevention strategies. This study using a nationwide database aims to investigate predictors and outcomes of NE and HAC after kidney transplantation using appropriate events for the kidney transplant procedure according to both NQF and CMS lists.

\section{Methods}

An analysis of the nationwide inpatient sample (NIS) databaseduring 2002 -2012 was used in this study. NIS is an inpatient care database according to hospital discharge data in the USA acquired by the Healthcare Cost and Utilization Project (HCUP) of the Agency for Healthcare Research and Quality, Rockville, Maryland. It is an annually compiled database which consists of approximately 8 million inpatient stays from approximately 1000 hospitals each year ${ }^{5}$. The informed consent is obtained from individual patients within the individual hospitals' patient consent forms by NIS. For the purposes of this study, NIS was queried using the Ninth Revision of the International Classification of Disease (ICD-9-CM) procedure code of 55.69 to identify the cases who underwent kidney transplantation. ICD-9 diagnosis codes which were reported in principal diagnosis of patients were also used to identify relevant diagnoses of patients.This study investigated Never Events and Hospital Acquired Conditions (HAC) after kidney transplantation using the ICD-9 diagnosis codes which were reported as the second to 25th diagnosis of patients in the database. Details of the codes which were used to identify NE and 
HAC were reported in Table 1. The definition of complications (NE and HAC) were according to ICD-9 diagnosis codes which is available online ${ }^{6}$.

Patient variables include demographic data (age, sex, and race), patient diagnosis, comorbidities (such as hypertension, coagulopathy, and diabetes mellitus), hospitalization length, total hospital charges, and admission type (elective vs. non-elective). Patients loss of function before surgery and risk of mortality (mild, moderate, major, and extreme) were according to the classification of the NIS database which is available on www.hcup-us.ahrq.gov ${ }^{5}$. The primary end points were rates of NE and HAC after kidney transplantation. Secondary end points were predictors and outcomes of NE and HAC after kidney transplantation. Risk adjusted analysis was performed to investigate predictors and outcomes of NE and HAC.

Statistical Analysis

Data was analyzed using the Statistical Package for Social Sciences (SPSS) software, Version 22 (SPSS Inc., Chicago, IL) . The main analysis was multivariate analysis using logistic regression. The associations of NE and HAC with mortality and morbidity of patients were examined using a multivariable logistic regression model. We included all the variables of the study as covariates in the model. The estimated adjusted odds ratio (AOR) with a 95\% confidence interval was calculated for each correlation. Statistical hypotheses were tested using $\mathrm{P}<0.05$ as the level of statistical significance.

\section{Results}

We sampled 35,058 patients who underwent kidney transplant during 2002-2012 accordng to the NIS database. Of these $60.2 \%$ were male. The median age of patient was 50 years. Also, the majority of patients were Caucasian (53.8\%). Deficiency anemia (41.2\%) and fluid and electrolyte disorders (31.8\%) were the most common reported comorbid conditions of patients. The median hospitalization length of patients was 6 days. The most common reported reasons of renal failure as well as need to kidney transplant were hypertension (42\%) and diabetes (34.7\%). Demographics and clinical characteristics of patients are shown in Table 2.

Among patients who underwent kidney transplant 11 patients (0.03\%) had Never Events and all of the events were due to retained foreign bodies. Overall, 138 patients had postoperative HAC. Of which falling was the most common event (44.9\%) followed by poor glycemic control (21.7\%), vascular catheter-associated infection (21\%), catheter-associated urinary tract infection (8\%), stages III \& IV pressure ulcers (2.9\%), and ABO incompatible blood transfusion (2.2\%) (Figure 1).

The mortality and morbidity of patients who underwent kidney transplantation were $0.5 \%$ and $24.3 \%$ respectively. Patients with HAC or NE had significantly higher mortality ( $1.4 \%$ vs. $0.5 \%, \mathrm{P}=0.04$ ) and morbidity ( $45.6 \%$ vs. $24.2 \%, \mathrm{P}<0.01$ ). HAC and NE after surgery were significantly associated with an increased mean length of stay (13 days vs. 7 days, $\mathrm{P}<0.01$ ), and hospital charges of patients ( $\$ 231801 v s$. $\$ 146717, \mathrm{P}<0.01$ ). Also, patients with NE or HAC had a higher risk of unplanned reoperation (AOR: 1.92, $\mathrm{P}=0.04$ ), prolonged ileus (AOR: 2.28, 
$\mathrm{P}<0.01$ ), pneumonia (AOR: 3.31, $\mathrm{P}<0.01$ ), acute myocardial infarction (AOR: 2.72, $\mathrm{P}<0.01$ ), and respiratory failure (AOR: 3.69, $\mathrm{P}<0.01$ ) (Table 3).

Risk adjusted analysis of factors associated with postoperative NE and HAC were reported in Table 4. A significantly higher risk of HAC or NE events was seen for patients who had a severe disease before surgery (AOR: $3.25, \mathrm{P}<0.01$ ) and patients who were expected to have more loss of function before surgey (AOR: 1.62, $\mathrm{P}=0.03$ ). When investigating patients who had catheter related urinary tract infection, factors such as age (AOR: 0.96, CI: 0.92-0.99, $\mathrm{P}=0.04$ ), female gender (AOR: 15.48, CI: 1.92-124.41, $\mathrm{P}=0.01$ ), and severity of loss of function before surgey (AOR: 9.70, CI: 1.01-94.88, $\mathrm{P}=0.04$ ) were significantly associated with catheter related urinary tract infection. Also, severity of loss of function before surgey was significantly associated with falling (AOR: 3.14, CI:1.48-6.67, $\mathrm{P}<0.01$ ), retained foreign body (AOR: 7.58, CI: 1.24-46.28, $\mathrm{P}=0.02$ ), and vascular catheter-associated infection (AOR: 6.82, CI: 1.22-38.05, $\mathrm{P}=0.02$ ). Poor glycemic control was significantly associated with patient's age (AOR: 0.94, CI: 0.91-0.98, $\mathrm{P}<0.01)$.

\section{Discussion}

This study found a significant increase in mortality, morbidity, hospitalization length, and total hospital charges of patients with never events and hospital acquired conditions after kidney transplant. Also, the risks of other postoperative complications such as prolonged ileus, pneumonia, acute myocardial infarction, and respiratory failure increase in presense of NE and HAC. We reinforce the literatures reports on the severity effect of NE and HAC events on outcomes of patient as well as the significant increase in total hospital charges related to the events ${ }^{7-9}$.

Our study results show the severity of loss of function before surgey is a reliable factor to find high risk patients for post operative NE and HAC (Table 4). We found the risk of NE and HAC for patients with major or extreme loss of function before surgey is more than three times compared to patients with minor or moderate loss of function before surgery. Patient characteristics has been reported as an important predictor of the occurrence of never event by literature ${ }^{10}$. Although preventive sterategies should be done for all surgical patients, some high risk patients may benefit from frequent assess to decrease the risk of never events during hospitalization. For example, creating a mandatory check list includig practical methods in prevention of NE and HAC that should be filled frequently during hospitalization by the responsible surgeon may be usefull in high risk patients ${ }^{2}$.

We found a significant association between catheter related urinary tract infection and age, female gender, and severity of loss of function before surgey which is in line with literaure reports ${ }^{11,12}$. However, we could not evaluate correlation between urinary stent and length of using urinary catheter and urinay tract infection. It is estimated that up to $69 \%$ of catheter related urinary tract infection can be prevented using appropriate infection prevention strategies such as the removal of the catheter as soon as possible or avoidance of its use ${ }^{12-14}$. Considering $38 \%$ of physicians were not aware of the status of urinary catheter use for their patients ${ }^{12,15}$, reminder 
systems including face-to-face reminders involving staff nurses and virtual reminders involving the use of electronic devices may help decrease the risk of catheter related urinary tract infection ${ }^{12}$.

Our study results show falling is the most common preventable HAC in kidney transplant patients. The overall reported rate of fall after generl surgery procedures is $1.6 \%$ in literature ${ }^{16}$. We found $0.2 \%$ for the rate of post operative fall for kidney transplant patients which is lower than the general surgery procedures. Although the fall seems like a simple event, it represents a failure of multiple physiological systems and also a marker for increased perioperative mortality and morbidity and postoperative delirium in literatures ${ }^{16-19}$. Recognition of fall risk factors and identifying high risk patients for fall will help design postoperative fall prevention programs. Factors such as older age, functional dependence, and lower albumin leve have been reported to be associated with fall in literature ${ }^{16}$. We also found a higher risk of fall for patients who had more loss of function before surgey. Interestingly $66 \%$ of patients who fell had diabetes as a result of kiney failure. Diabetes with peripheral neuropathy can increase chance of fall after surgery. Minimizing polypharmacy and avoiding individual medications which increase the risk of delirium, increasing the presence of family members or sitters at the bedside, minimizing environmental hazards, and occupational and physical therapy training in high-risk patients especialy in diabetetic patients with peripheral neuropathy may decrease the risk of fall in high risk patients.

We found vascular catheter-associated infection as the third most common HAC after kidney transplant. It has been estimated that there are 15 million central vascular catheter days for patients hospitalized at intensive care units each year in the US ${ }^{20,21}$. There are multiple studies that addressed catheter-related bloodstream infections in literature ${ }^{20,21}$. Factors such as the duration of catheterization and use of a semipermeable transparent dressing were reported to be independently associated with positive cultures of catheters in literature ${ }^{22}$. We found a significantly higher risk of vascular catheter-associated infection in patients who had more loss of function before surgey. Following guidelines for the prevention of intravascular catheterrelated infections can decrease the risk of vascular catheter-associated infection in surgical patients ${ }^{21}$. Some evidence-based recommendations include: educating and designating trained healthcare personnel and assessing their knowledge and adherence to guidelines, correcting selection of catheters and sites, hand hygiene and aseptic techniques, maximal sterile barrier precautions, and appropriate catheter site dressing regimens ${ }^{21}$.

This study results show poor glycemic control is the second most common HAC in kidney transplant patient and it is reversly associated with patient's age. Perioperative hyperglycemia has been reported as an adverse outcome predictor in surgical patients in literature even in non-diabetic patients ${ }^{23,24}$. It has been reported that postoperative blood glucose greater than $140 \mathrm{mg} / \mathrm{dL}$ is present in as many as $40 \%$ of noncardiac surgery patients, and $25 \%$ of those patients have a blood glucose level greater than $180 \mathrm{mg} / \mathrm{dL}^{24}$. Checking the blood glucose in the morning of surgery in patients with and without a history of diabetes is recommended in 
literature ${ }^{23}$. The blood glucose levels of $150 \mathrm{mg} / \mathrm{dl}$ has been reported as the cut off point for increasing risks of mortality, morbidity, and hospitalization length in literature, particularly in those who did not have a prior diagnosis of diabetes ${ }^{24}$. Perioperative immunosupresive medications such as corticosteroids and prograf also can increase blood sugar of transplanted patients and make control of blood sugar in such patients difficult. However, further studies are indicated to determine whether strict perioperative blood glucose management improves clinical outcomes in transplanted patients.

\section{Study limitations}

There are limitations to the study. Detection of adverse events in NIS database is limited to the ICD-9-CM coding system and coding error is possible ${ }^{25,26}$. Despite our attempts to adjust for all possible confounders, we could not measure some variables that contribute to patient outcomes such as warm and cold ischemia time, presence of urinary stent, effects of perioperative immunosupresive medications, and length of using urinary catheter. The NIS dataset misses some potentially important explanatory variables such as anatomic or laboratory data. Also, The NIS has no ability to follow patient outcomes longitudinally. Despite these limitations, the advantage of using the NIS database is the broad national geographic representation across all regions of the country and also the possibility of reporting weighted results as national outcomes.

\section{Conclusion}

HAC and NE after kidney transplantation are uncommon. However, they are associated with a significant increase in mortality, morbidity, hospitalization length, hospital charges, and reoperation of patients. Quality improvement initiatives should target HAC and NE in order to successfully reduce or prevent these events. The severity of loss of function before surgey is a reliable factor to identify high risk patients for post operative NE and HAC. Falling is the most common preventable HAC in kidney transplant patients. The severity of loss of function before surgey is significantly associated with falling, retained foreign body, catheter related urinary tract infection, and vascular catheter-associated infection. The risks of poor glycemic control and catheter related urinary tract infection significantly increase in elderly. Following guideline's recommendations in prevention of HAC and NE may decrease the rates of NE and HAC in high risk patients. 


\section{References}

1. Teufack SG, Campbell P, Jabbour P, Maltenfort M, Evans J, Ratliff JK. Potential financial impact of restriction in "never event" and periprocedural hospital-acquired condition reimbursement at a tertiary neurosurgical center: a single-institution prospective study. J Neurosurg. 2010;112(2):249-256.

2. Lembitz A, Clarke TJ. Clarifying "never events and introducing "always events". Patient Saf Surg. 2009;3:26.

3. Nero DC, Lipp MJ, Callahan MA. The financial impact of hospital-acquired conditions. $J$ Health Care Finance. 2012;38(3):40-49.

4. Mehtsun WT, Ibrahim AM, Diener-West M, Pronovost PJ, Makary MA. Surgical never events in the United States. Surgery. 2013;153(4):465-472.

5. HCUP Nationwide Inpatient Sample (NIS). Healthcare Cost and Utilization Project (HCUP). 2000-2010. Agency for Healthcare Research and Quality, Rockville, MD.www.hcup-us.ahrq.gov/nisoverview.jsp.

6. The International Classification of Diseases Nr, Clinical Modification: ICD-9-CM. 4th ed. Washington, DC, Services USDoHaH, 1991 Aahwidc.

7. Shah NK, Farber A, Kalish JA, et al. Occurrence of "never events" after major open vascular surgery procedures. J Vasc Surg. 2016;63(3):738-745.e728.

8. Wen T, He S, Attenello F, et al. The impact of patient age and comorbidities on the occurrence of "never events" in cerebrovascular surgery: an analysis of the Nationwide Inpatient Sample. J Neurosurg. 2014;121(3):580-586.

9. Wen T, Pease M, Attenello FJ, et al. Evaluation of Effect of Weekend Admission on the Prevalence of Hospital-Acquired Conditions in Patients Receiving Cervical Fusions. World Neurosurg. 2015;84(1):58-68.

10. Fry DE, Pine M, Jones BL, Meimban RJ. Patient characteristics and the occurrence of never events. Arch Surg. 2010;145(2):148-151.

11. Guggenbichler JP, Assadian O, Boeswald M, Kramer A. Incidence and clinical implication of nosocomial infections associated with implantable biomaterials - catheters, ventilator-associated pneumonia, urinary tract infections. GMS Krankenhhyg Interdiszip. 2011;6(1):Doc18.

12. Tambyah PA, Oon J. Catheter-associated urinary tract infection. Curr Opin Infect Dis. 2012;25(4):365-370.

13. Reed D, Kemmerly SA. Infection control and prevention: a review of hospital-acquired infections and the economic implications. Ochsner J. 2009;9(1):27-31.

14. Rebmann T, Greene LR. Preventing ventilator-associated pneumonia: An executive summary of the Association for Professionals in Infection Control and Epidemiology, Inc, Elimination Guide. Am J Infect Control. 2010;38(8):647-649.

15. Saint S, Wiese J, Amory JK, et al. Are physicians aware of which of their patients have indwelling urinary catheters? Am J Med. 2000;109(6):476-480. 
16. Church S, Robinson TN, Angles EM, Tran ZV, Wallace JI. Postoperative falls in the acute hospital setting: characteristics, risk factors, and outcomes in males. Am J Surg. 2011;201(2):197-202.

17. Robinson TN, Eiseman B, Wallace JI, et al. Redefining geriatric preoperative assessment using frailty, disability and co-morbidity. Ann Surg. 2009;250(3):449-455.

18. Dasgupta M, Dumbrell AC. Preoperative risk assessment for delirium after noncardiac surgery: a systematic review. J Am Geriatr Soc. 2006;54(10):1578-1589.

19. Robinson TN, Raeburn CD, Tran ZV, Angles EM, Brenner LA, Moss M. Postoperative delirium in the elderly: risk factors and outcomes. Ann Surg. 2009;249(1):173-178.

20. Mermel LA. Prevention of intravascular catheter-related infections. Ann Intern Med. 2000;132(5):391-402.

21. O'Grady NP, Alexander M, Burns LA, et al. Guidelines for the prevention of intravascular catheter-related infections. Clin Infect Dis. 2011;52(9):e162-193.

22. Richet H, Hubert B, Nitemberg G, et al. Prospective multicenter study of vascularcatheter-related complications and risk factors for positive central-catheter cultures in intensive care unit patients. J Clin Microbiol. 1990;28(11):2520-2525.

23. Kwon S, Thompson R, Dellinger P, Yanez D, Farrohki E, Flum D. Importance of perioperative glycemic control in general surgery: a report from the Surgical Care and Outcomes Assessment Program. Ann Surg. 2013;257(1):8-14.

24. Frisch A, Chandra P, Smiley D, et al. Prevalence and clinical outcome of hyperglycemia in the perioperative period in noncardiac surgery. Diabetes Care. 2010;33(8):1783-1788.

25. Lorence DP, Ibrahim IA. Benchmarking variation in coding accuracy across the United States. J Health Care Finance. 2003;29(4):29-42.

26. Berthelsen CL. Evaluation of coding data quality of the HCUP National Inpatient Sample. Top Health Inf Manage. 2000;21(2):10-23. 
Figures and Tables

Fig. 1. Never events and hospital-acquired conditions after kidney transplant.

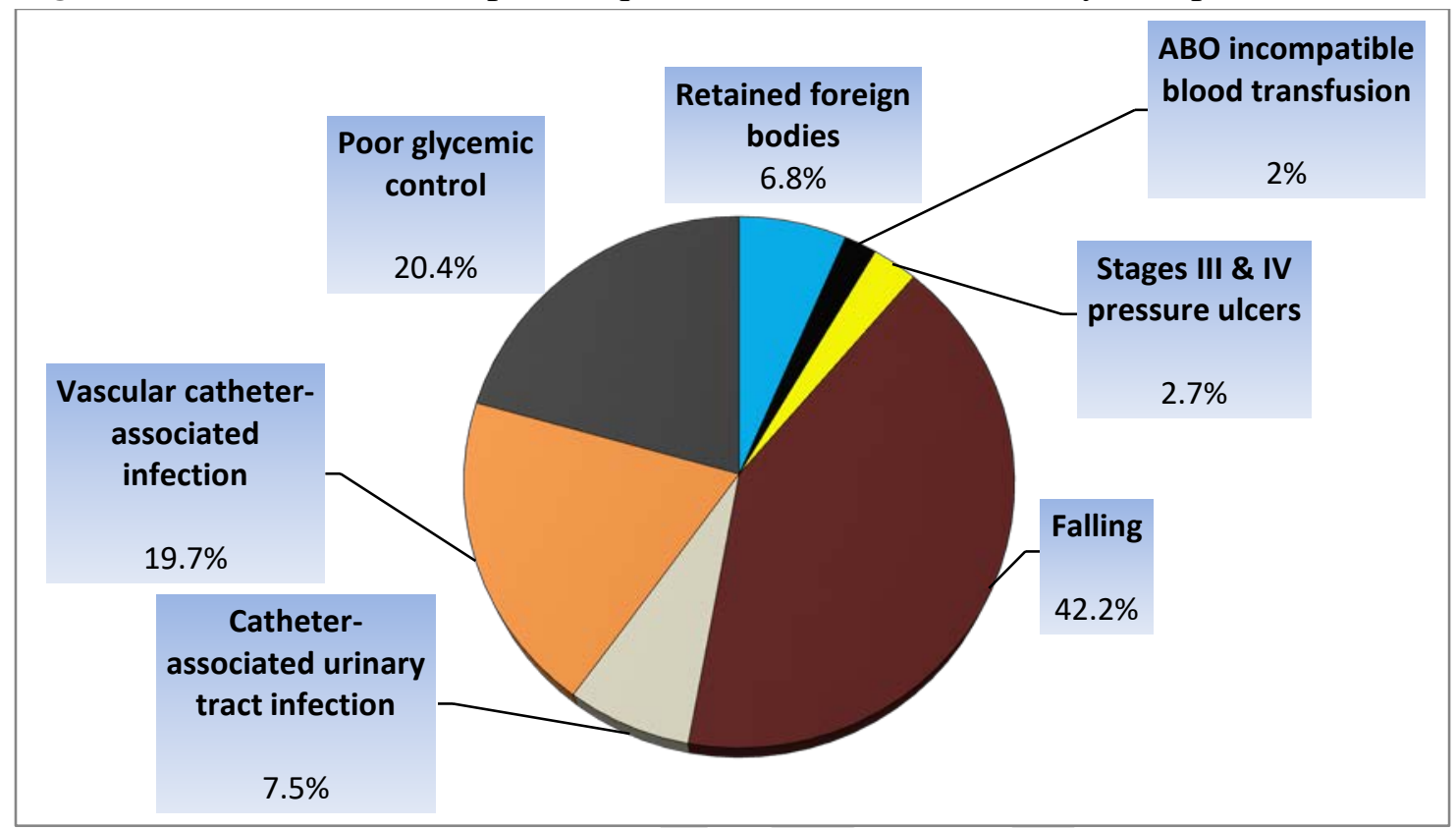

\begin{tabular}{|l|l|}
\hline \multicolumn{2}{|l|}{ Table 1. Hospital-acquired conditions and never events identification codes } \\
\hline Diagnosis & ICD-9 codes * \\
\hline Hospital-acquired conditions (HAC) \\
\hline Air Embolism & 999.1 \\
\hline Blood Incompatibility & $999.60,999.61,999.62,999.63,999.69$ \\
\hline Pressure Ulcer Stages III \& IV & $707.23,707.24$ \\
\hline Falls and Trauma & $800-829$ 830-839 850-854 925-929 940-949 991-994 \\
\hline $\begin{array}{l}\text { Catheter-Associated Urinary Tract } \\
\text { Infection (UTI) }\end{array}$ & 996.64 \\
\hline Vascular Catheter-Associated Infection & $999.31,999.32,999.33$ \\
\hline \begin{tabular}{l|l|} 
Poor Glycemic Control \\
Never events
\end{tabular} & $250.10-250.13,250.20-250.23,251.0,249.10-249.11$, \\
\hline Retained Foreign body & E871.0, E871.9, 998.4, 998.7 \\
\hline Wrong operation on correct patient & E876.5 \\
\hline $\begin{array}{l}\text { Wrong operation intended for another } \\
\text { patient }\end{array}$ & E876.6 \\
\hline $\begin{array}{l}\text { Correct operation on wrong body } \\
\text { part/site }\end{array}$ & E876.7 \\
\hline
\end{tabular}




\begin{tabular}{|c|c|c|c|c|}
\hline \multicolumn{2}{|l|}{ Variables } & \multirow{2}{*}{\begin{tabular}{|l|}
$\begin{array}{l}\text { Patients with } \\
\text { NE * or HAC** }\end{array}$ \\
$48 \pm 16$
\end{tabular}} & \multirow{2}{*}{$\begin{array}{l}\text { Patients without } \\
\text { NE or HAC } \\
47 \pm 15\end{array}$} & \multirow{2}{*}{$\begin{array}{l}\mathbf{p} \\
<0.01\end{array}$} \\
\hline Age & $\begin{array}{l}\text { Mean } \pm \text { Standard Deviation } \\
\text { (year) }\end{array}$ & & & \\
\hline & Median (year) & 50 & 50 & --- \\
\hline Sex & Female & $41.5 \%$ & $39.8 \%$ & 0.67 \\
\hline \multirow{5}{*}{ Race } & White & $65.9 \%$ & $44.6 \%$ & $<0.01$ \\
\hline & Black or African American & $20.3 \%$ & $18.3 \%$ & 0.64 \\
\hline & Hispanic & $8.9 \%$ & $12.8 \%$ & 0.04 \\
\hline & Asian & $0.8 \%$ & $3.8 \%$ & 0.97 \\
\hline & Other or unknown & $4.1 \%$ & $20.5 \%$ & 0.04 \\
\hline \multirow{11}{*}{ Comorbidity } & $\begin{array}{l}\text { Fluid and electrolyte } \\
\text { disorders }\end{array}$ & $37.7 \%$ & $31.8 \%$ & 0.12 \\
\hline & Coagulopathy & $12.3 \%$ & $7.1 \%$ & 0.01 \\
\hline & Deficiency anemia & $40.4 \%$ & $41.2 \%$ & 0.84 \\
\hline & Diabetes & $47.6 \%$ & $23.9 \%$ & $<0.01$ \\
\hline & Liver disease & $5.5 \%$ & $3.1 \%$ & 0.08 \\
\hline & Weight loss & $2.1 \%$ & $1.2 \%$ & 0.38 \\
\hline & Hypertension & $14.4 \%$ & $10.8 \%$ & 0.16 \\
\hline & Chronic pulmonary disease & $5.4 \%$ & $5.6 \%$ & 0.94 \\
\hline & Obesity & $5.5 \%$ & $7.5 \%$ & 0.34 \\
\hline & Congestive heart failure & $5.4 \%$ & $4.9 \%$ & 0.74 \\
\hline & $\begin{array}{l}\text { Peripheral vascular } \\
\text { disorders }\end{array}$ & $7.5 \%$ & $4.8 \%$ & 0.12 \\
\hline \multirow{4}{*}{$\begin{array}{l}\text { Preoperative } \\
\text { expected } \\
\text { mortality }\end{array}$} & Minor likelihood of dying & $7.9 \%$ & $32.5 \%$ & $<0.01$ \\
\hline & $\begin{array}{l}\text { Moderate likelihood of } \\
\text { dying }\end{array}$ & $47.4 \%$ & $46.7 \%$ & $<0.01$ \\
\hline & Major likelihood of dying & $30.7 \%$ & $17.8 \%$ & $<0.01$ \\
\hline & Extreme likelihood of dying & $14 \%$ & $3.1 \%$ & $<0.01$ \\
\hline \multirow{4}{*}{$\begin{array}{l}\text { Preoperative } \\
\text { loss of function }\end{array}$} & Minor loss of function $* * *$ & $3.5 \%$ & $15.7 \%$ & $<0.01$ \\
\hline & Moderate loss of function & $27.2 \%$ & $46.6 \%$ & $<0.01$ \\
\hline & Major loss of function & $45.6 \%$ & $32.2 \%$ & $<0.01$ \\
\hline & Extreme loss of function & $23.7 \%$ & $5.5 \%$ & $<0.01$ \\
\hline \multirow{2}{*}{$\begin{array}{l}\text { Indication of } \\
\text { kidney }\end{array}$} & Hypertension & $23.1 \%$ & $42.1 \%$ & $<0.01$ \\
\hline & Diabetes Mellitus & $63.9 \%$ & $34.6 \%$ & $<0.01$ \\
\hline
\end{tabular}




\begin{tabular}{|c|c|c|c|c|}
\hline \multirow[t]{4}{*}{ transplant } & $\begin{array}{l}\text { Previous kidney transplant } \\
\text { failure }\end{array}$ & $5.4 \%$ & $6.1 \%$ & 0.72 \\
\hline & Polycystic kidney disease & $1.4 \%$ & $3.3 \%$ & 0.19 \\
\hline & Lupus erythematous & $0 \%$ & $1.5 \%$ & 0.13 \\
\hline & Other & $6.1 \%$ & $12.4 \%$ & 0.09 \\
\hline \multirow{2}{*}{$\begin{array}{l}\text { Admission } \\
\text { Type }\end{array}$} & Elective & $54.4 \%$ & $54.8 \%$ & 0.92 \\
\hline & Non-elective & $45.6 \%$ & $45.2 \%$ & 0.92 \\
\hline \multirow{2}{*}{$\begin{array}{l}\text { Hospitalization } \\
\text { length }\end{array}$} & $\begin{array}{l}\text { Mean } \pm \text { Standard Deviation } \\
\text { (day) }\end{array}$ & $13 \pm 11$ & $7 \pm 7$ & $<0.01$ \\
\hline & Median (day) & 8 & 6 & $<0.01$ \\
\hline \multirow{2}{*}{$\begin{array}{l}\text { Total hospital } \\
\text { charges }\end{array}$} & Mean \pm Standard Deviation & $\$ 231801 \pm 216093$ & $\$ 146717 \pm 97759$ & $<0.01$ \\
\hline & Median & 156647 & $\$ 124184$ & $<0.01$ \\
\hline \multirow{2}{*}{ Outcomes } & Mortality & $1.4 \%$ & $0.5 \%$ & $<0.01$ \\
\hline & Overall Morbidity & $45.6 \%$ & $24.2 \%$ & $<0.01$ \\
\hline
\end{tabular}

\begin{tabular}{|c|c|c|c|c|c|}
\hline Complications & $\begin{array}{c}\text { Patients } \\
\text { with NEor } \\
\text { HAC }\end{array}$ & $\begin{array}{c}\text { Patients } \\
\text { without NE } \\
\text { or HAC }\end{array}$ & $\begin{array}{c}\text { Adjusted } \\
\text { odd } \\
\text { ratio }\end{array}$ & $\begin{array}{c}95 \% \\
\text { confidence } \\
\text { interval }\end{array}$ & $\mathbf{p}$ \\
\hline Mortality & $1.4 \%$ & $0.5 \%$ & 2.49 & $1.01-10.31$ & 0.04 \\
\hline Overall Morbidity* & $45.6 \%$ & $24.2 \%$ & 2.44 & $1.74-3.42$ & $<0.01$ \\
\hline $\begin{array}{l}\text { Transplanted kidney } \\
\text { failure or rejection }\end{array}$ & $10.2 \%$ & $8.2 \%$ & 1.23 & $0.71-2.12$ & 0.45 \\
\hline $\begin{array}{l}\text { Renal vascular } \\
\text { complications }\end{array}$ & $2.7 \%$ & $0.6 \%$ & 3.83 & $1.38-10.64$ & 0.01 \\
\hline Wound disruption & $3.4 \%$ & $0.5 \%$ & 5.74 & $2.28-14.41$ & $<0.01$ \\
\hline $\begin{array}{l}\text { Hemorrhagic } \\
\text { complications }\end{array}$ & $7.5 \%$ & $5.2 \%$ & 1.28 & $0.68-2.41$ & 0.43 \\
\hline Ureter complications & $4.1 \%$ & $3.4 \%$ & 1.19 & $0.52-2.71$ & 0.67 \\
\hline Unplanned reoperation & $5.4 \%$ & $2.2 \%$ & 1.92 & $1.01-4.02$ & 0.04 \\
\hline Prolonged Ileus & $10.9 \%$ & $4.7 \%$ & 2.28 & $1.34-3.88$ & $<0.01$ \\
\hline Urinary Tract Infection & $15.6 \%$ & $3.9 \%$ & 4.03 & $2.54-6.41$ & $<0.01$ \\
\hline Wound Infection & $2.7 \%$ & $0.8 \%$ & 2.63 & $0.94-7.38$ & 0.06 \\
\hline Pneumonia & $4.1 \%$ & $1.1 \%$ & 3.31 & $1.43-7.67$ & $<0.01$ \\
\hline $\begin{array}{l}\text { Hospitalization }>30 \\
\text { Days }\end{array}$ & $8.2 \%$ & $1.1 \%$ & 6.16 & $3.22-11.79$ & $<0.01$ \\
\hline
\end{tabular}




\begin{tabular}{|l|c|c|c|c|c|}
\hline $\begin{array}{l}\text { Acute Myocardial } \\
\text { Infarction }\end{array}$ & $6.1 \%$ & $2 \%$ & 2.72 & $1.36-5.44$ & $<0.01$ \\
\hline $\begin{array}{l}\text { Acute Respiratory } \\
\text { Failure }\end{array}$ & $4.8 \%$ & $1.1 \%$ & 3.69 & $1.68-8.12$ & $<0.01$ \\
\hline Deep Vein Thrombosis & $0 \%$ & $0.3 \%$ & 0.99 & $0.99-1$ & 0.51 \\
\hline
\end{tabular}

*Includes: Transplanted kidney failure or rejection, renal vascular complications, wound disruption, hemorrhagic complications, ureter complications, unplanned reoperation, prolonged Ileus, urinary tract infection, unplanned reoperation, wound infection, pneumonia, hospitalization more than 30 Days, acute myocardial infarction, acute respiratory failure, deep vein thrombosis. HAC: hospital-acquired conditions; NE: never events.

\begin{tabular}{|c|c|c|c|c|}
\hline Variables & & $\begin{array}{l}\text { Adjusted } \\
\text { odds ratio }\end{array}$ & $\begin{array}{l}\text { 95\% confidence } \\
\text { interval }\end{array}$ & $\mathbf{p}$ \\
\hline Age & Age & 0.98 & $0.97-0.99$ & 0.03 \\
\hline Sex & Female & 1.10 & $0.75-1.61$ & 0.61 \\
\hline \multirow{11}{*}{ Comorbidity } & Obesity & 0.48 & $0.19-1.20$ & 0.12 \\
\hline & Coagulopathy & 0.76 & $0.38-1.44$ & 0.45 \\
\hline & Hypertension & 0.89 & $0.50-1.58$ & 0.70 \\
\hline & Diabetes Mellitus & 0.99 & $0.59-1.66$ & 0.99 \\
\hline & $\begin{array}{l}\text { Fluid and Electrolyte } \\
\text { Abnormalities }\end{array}$ & 0.78 & $0.52-1.18$ & 0.24 \\
\hline & Chronic Lung Disease & 0.94 & $0.41-2.16$ & 0.89 \\
\hline & Weight Loss & 0.77 & $0.18-3.19$ & 0.72 \\
\hline & Deficiency Anemia & 0.89 & $0.60-1.32$ & 0.57 \\
\hline & Congestive Heart Failure & 0.50 & $0.20-1.26$ & 0.14 \\
\hline & Peripheral Vascular Disorders & 1.05 & $0.51-2.24$ & 0.87 \\
\hline & Liver Disease & 1.32 & $0.53-3.29$ & 0.54 \\
\hline \multirow{2}{*}{$\begin{array}{l}\text { Preoperative } \\
\text { expected } \\
\text { mortality }\end{array}$} & $\begin{array}{l}\text { Low or moderate likelihood of } \\
\text { dying }\end{array}$ & Reference & Reference & Reference \\
\hline & $\begin{array}{l}\text { High or extreme high likelihood of } \\
\text { dying }\end{array}$ & 1.62 & $1.03-2.55$ & 0.03 \\
\hline \multirow{2}{*}{$\begin{array}{l}\text { Preoperative } \\
\text { loss of function }\end{array}$} & Minor or moderate loss of function & Reference & Reference & Reference \\
\hline & Major or extreme loss of function & 3.25 & $1.95-5.41$ & $<0.01$ \\
\hline
\end{tabular}

